\title{
A NEW RADIOCARBON PRETREATMENT METHOD FOR MOLLUSCAN SHELL USING DENSITY FRACTIONATION OF CARBONATES IN BROMOFORM
}

\author{
Christopher M Russo ${ }^{1}$ Jennifer A Tripp ${ }^{1,2} \cdot$ Katerina Douka $^{3}$ • Thomas F G Higham ${ }^{3}$
}

ABSTRACT. Coastal archaeological sites that lack organic remains for radiocarbon dating are often abundant sources of molluscan shells. As a substitute for materials such as bone and charcoal, shells can be analyzed with ${ }^{14} \mathrm{C}$ dating to determine a site's age. Despite their being convenient, non-mobile archaeological artifacts, molluscan shells are plagued by several issues, including carbonate remodeling, in which aragonite in shells is converted to calcite as predicted by thermodynamics. We present here a carbonate density separation technique that addresses the issue of carbonate remodeling. Using a density fractionation with bromoform, aragonite concentrations are enriched in shells that have undergone significant remodeling. The technique has been applied to archaeological shells and has returned dates that are younger than those previously determined for the same shells.

\section{INTRODUCTION}

Radiocarbon dating of organic materials such as charcoal and bone collagen offer accurate chronological determinations at a variety of archaeological sites. However, at sites where organic preservation is poor, alternate materials or dating techniques are required. Coastal sites typically have shortages of organic remains for ${ }^{14} \mathrm{C}$ dating, but because these sites often include shell middens, accurate dates of shell carbonate provide a way to date these sites. In addition, because mollusks are processed soon after death and their remains are seldom transported long distances, the material offers a close correlation to archaeological events.

Accurate ${ }^{14} \mathrm{C}$ dates of molluscan shells (marine, aquatic, or terrestrial) are notoriously difficult to obtain, mainly due to allochthonous carbon integrated into the carbonate crystals during diagenesis. Marine shells have the added difficulty of the reservoir effect, which produces ${ }^{14} \mathrm{C}$ dates older than their "true" historic date. If preserved organic materials are available at a site, then these will usually be used for dating; however, development of a demonstrably reliable ${ }^{14} \mathrm{C}$ dating method for shell is important for building chronologies at sites with poor or no organic preservation.

Difficulty in dating marine molluscan shells stems from 2 main issues: the marine reservoir effect and carbonate remodeling during diagenesis (Schmidt 2000). The marine reservoir effect results from a combination of several factors, all of which cause marine shells (along with other marine organisms and those who consume them) to appear too old. This occurs by the incorporation of ${ }^{14} \mathrm{C}$ depleted carbon into the shell carbonate during the life of the animal. The old carbon may be the result of drainage of water over limestone formations into lakes, rivers, and the intertidal zone (the "hardwater effect"), the "upwelling" of old carbon from the deep ocean, the differential age of dissolved carbon dioxide in the ocean compared to the atmosphere, or a combination of these factors. Because none of these effects can be prevented, they must be corrected for, and indeed there are methods for doing so (Berger et al. 1966; Mangerud 1972; Stuiver and Braziunas 1993; Higham and Hogg 1995; Reimer and Reimer 2001; Reimer and McCormac 2002).

\footnotetext{
${ }^{1}$ Department of Chemistry, University of Scranton, 800 Linden St., Scranton, Pennsylvania 18510, USA.

${ }^{2}$ San Francisco State University, Department of Chemistry \& Biochemistry, 1600 Holloway Avenue, San Francisco, California 94132, USA. Corresponding author. Email: tripp@sfsu.edu.

${ }^{3}$ Oxford Radiocarbon Accelerator Unit, RLAHA, Dyson Perrins Building, South Parks Road, University of Oxford, Oxford, OX1 3QY, United Kingdom.
}

(C) 2010 by the Arizona Board of Regents on behalf of the University of Arizona Proceedings of the 20th International Radiocarbon Conference, edited by A J T Jull RADIOCARBON, Vol 52, Nr 2-3, 2010, p 1301-1311 
Molluscan shells are mostly comprised of calcium carbonate, though this compound may exist in different crystal structures, or polymorphs (Kato et al. 2003). There are 3 polymorphs of calcium carbonate; calcite and aragonite are the most common (Falini et al. 1996). Vaterite is a third polymorph, but it is far less stable than the other 2 and is usually not considered in the discussion of major molluscan carbonates. In these materials, calcium ions are located in similar positions in the crystal lattice, but a variation in the arrangement of the carbonate ions gives aragonite an orthorhombic structure (dal Negro and Ungaretti 1971), while calcite takes on a rhombohedral structure (Wyckoff 1964). It is also true that calcite is more stable than aragonite under standard conditions (Burns and Bredig 1956), but this does not mean that the formation of calcite is automatically favored over the formation of aragonite in nature.

Many mollusks form shells composed exclusively of aragonite, though others may incorporate both polymorphs into their shells (Bøggild 1930; Watabe 1988). The salinity of the water in which mollusks live is considered to have an effect on the concentration of aragonite or calcite (Hubbard and McManus 1981). Shell formation may also be influenced by biomolecules such as chitin (Peters 1972) and conchiolin (Mutvei 1969). In general, aragonite is found in shells more often than calcite is (Watabe 1988).

High temperatures above $350^{\circ} \mathrm{C}$ expedite the thermodynamic conversion of aragonite to calcite, the more stable phase, through recrystallization (Pruna et al. 1948). This transformation is quite slow below $150{ }^{\circ} \mathrm{C}$, but research has shown that aragonite in shells and corals can convert to calcite in ambient ocean conditions, with recrystallization ranging from 1 to $21 \%$ in shells over $70,000 \mathrm{yr}$ (Chappell and Polach 1972). Calcite, being more stable, can also precipitate from dissolved oceanic carbonates and deposit onto shells. Though most aragonite samples do not show more than 5\% calcite contamination, ${ }^{14} \mathrm{C}$ levels may still be skewed due to the fact that calcite found in shells is likely to contain environmental carbon of a different age than the biologically formed aragonite. Research has shown that contaminated shells do return inaccurate ${ }^{14} \mathrm{C}$ ages (Chappell and Polach 1972; Goslar and Pazdur 1985; Yates 1986).

While recrystallized shells are routinely excluded from ${ }^{14} \mathrm{C}$ analysis, until recently no serious attempts have been made to rectify the problem of shell recrystallization by separating the 2 polymorphs of calcium carbonate. The method of heavy liquid density fractionation has been said to be "laborious and inappropriate for precise microscale sampling," though with no substantiation (Kato et al. 2003). We have therefore pursued and developed an effective carbonate density separation method for the separation and isolation of molluscan shell aragonite from calcite using bromoform. Density fractionation of shell carbonates as a pretreatment method for accelerator mass spectrometry (AMS) ${ }^{14} \mathrm{C}$ dating was first proposed by Tripp and Higham in 2005. The method described below is similar to another published in these proceedings by Douka et al. (2010) using polytungstates as the separation solvent. Groups at the University of Scranton and the Oxford Radiocarbon Accelerator Unit have been working independently towards the same goal of perfecting a suitable separation technique. In this paper, we follow terminology coined by Douka et al. (2010) in calling the carbonate density separation method by the acronym CarDS.

While density fractionation has never been reported as a ${ }^{14} \mathrm{C}$ pretreatment method for shells, it has been used for marine sediments (Henderson et al. 2001) and shells (Takenaka et al. 1999) in other applications. A similar approach has been taken for fractionating bone osteones by density (Bell et al. 2001; Shin 2007) The present method has been applied to ancient molluscan shells that have potentially undergone recrystallization so that their ${ }^{14} \mathrm{C}$ ages may be determined more accurately than before. 


\section{MATERIALS AND METHODS}

\section{Materials}

Whole calcite cleavages were purchased from Fisher Scientific, while clam shell (Tivela stultorum) was used as our aragonite reference ( $99.7 \%$ aragonite according to X-ray diffraction). The calcite did not require any chemical pretreatment, while the clam shell was soaked $50 \mathrm{~g}$ at a time overnight in $200 \mathrm{~mL} 50 \mathrm{wt} \%$ aqueous $\mathrm{NaOH}$ to remove protein. Previously dated ancient shells were acquired from the archives of the Oxford Radiocarbon Accelerator Unit, and we obtained the permission of the archaeologists involved where possible. All solvents were purchased from Sigma-Aldrich and used as supplied.

\section{Carbonate Grinding}

Large sample pieces were easily broken with a hammer down to sizes less than $3 \mathrm{~cm}$. Using a Spex SamplePrep 6750 Freezer/Mill mechanical grinder, up to $10 \mathrm{~g}$ of this broken sample was loaded into the grinder chamber. Keeping the sample at $-196{ }^{\circ} \mathrm{C}$ in a liquid nitrogen bath, the samples were ground with varying parameters where $\mathrm{T} 1=$ grinding time, $\mathrm{T} 2=$ cool-down time, $\mathrm{T} 3=$ precool time, and $\mathrm{CYC}=$ number of cycles. $\mathrm{T} 1$ and $\mathrm{T} 2$ were always $2.0 \mathrm{~min}$ each, $\mathrm{T} 3$ was 5.0 to $10.0 \mathrm{~min}$, and CYC ranged from 1 to 4 cycles.

After grinding, samples were sieved to isolate each by particle size. Sieves were purchased from Fisher Scientific with mesh sizes of 150, 106, 75, 53, and $38 \mu \mathrm{m}$ (ASTM E11 specification). Any sample material greater than $150 \mu \mathrm{m}$ was considered heterogeneous to the rest of the mixture and was discarded. Most samples were sieved with only the $150-\mu \mathrm{m}$ mesh.

\section{Carbonate Density Separation (CarDS)}

Following successful grinding and sieving to a homogeneous powder, carbonate samples were separated by density in a liquid medium. From 100 to $500 \mathrm{mg}$ of powdered sample was placed in a 10$\mathrm{mL}$ centrifuge tube. To the sample, $4.0 \mathrm{~mL}$ of bromoform $(99+\%)$ was added. Toluene was then added to reduce the solvent density. Typical toluene volumes that caused good separations ranged from 250 to $350 \mu \mathrm{L}$. For the ancient shells, $300 \mu \mathrm{L}$ of toluene was used, giving a solution with a density of $2.75 \mathrm{~g} / \mathrm{cm}^{3}$. The 2 layers were isolated by centrifugation in a Fisher Scientific Centrific Model 228 centrifuge, vacuum filtered, washed with dichloromethane, and dried under vacuum. In an effort to maximize carbonate fractionation, a second sequential separation could be performed on the 2 layers using a similar procedure to yield 4 layers.

\section{Analysis of Shells}

Quantitative infrared spectroscopy was used to determine the amount of aragonite in each fraction (Vagenas et al. 2002). Infrared spectra were taken with a Brukor Tensor 37 FT-IR spectrometer, fitted with a Pike MIRacle attenuated total reflectance stage equipped with a diamond crystal plate, in which the ground carbonates were measured directly. Our focus was on the low-energy fingerprint region from 1200 to $600 \mathrm{~cm}^{-1}$, specifically those peaks at 1083, 872, 855, 713, and $700 \mathrm{~cm}^{-1}$. Quantitative determination of aragonite and calcite weight fractions were determined with absorbance peak area ratios. The area of the $700-\mathrm{cm}^{-1}$ peak was subtracted from the whole $713-700 \mathrm{~cm}^{-1}$ region to obtain a more accurate area for the $713-\mathrm{cm}^{-1}$ peak. Integrations were performed automatically with Bruker Optik Opus software. A standard curve for binary aragonite-calcite mixtures was made using spectra from 10 reference samples that ranged from 10 to $100 \mathrm{wt} \%$ aragonite in calcite. 
$\mathrm{X}$-ray diffraction (XRD) is necessary for more accurate determinations of carbonate mineral than are producible with infrared spectroscopy. Approximately $30 \mathrm{mg}$ of powdered calcium carbonate was evenly coated over a plastic microscopy slide cover. Using a Philips PW 1820 X-Ray Diffractometer at the University of Oxford's Material Science department, the sample was scanned from $25^{\circ}$ to $35^{\circ}$ at a step rate of $0.02^{\circ}$ per 1.25 seconds. Further details of this method are described elsewhere in these proceedings (Douka et al. 2010).

Pretreatment of the carbonate samples for AMS dating was performed at the Oxford Radiocarbon Accelerator Unit using standard procedures. Approximately $30 \mathrm{mg}$ of each carbonate sample was reacted with $2-3 \mathrm{~mL}$ of $100 \%$ orthophosphoric acid in vacuo using a 2-armed Pyrex ${ }^{\circledR}$ reaction vessel. $\mathrm{CO}_{2}$ from the acid hydrolysis was cryogenically distilled and converted to graphite by reduction of $\mathrm{CO}_{2}$ over an iron catalyst in an excess $\mathrm{H}_{2}$ atmosphere (Bronk Ramsey and Hedges 1997). $\mathrm{CO}_{2}$ from the carbonate reaction was recycled through the mass spectrometer, purified, and then graphitized prior to AMS dating.

\section{RESULTS AND DISCUSSION}

\section{Carbonate Grinding}

The very first steps in the preparation of molluscan shells for ${ }^{14} \mathrm{C}$ dating involve the pulverization and homogenization of samples. One of the key goals of grinding shell samples is to pulverize the carbonates enough so that they can be accurately separated by density. Care must be taken when grinding carbonate samples to prevent aragonite from morphing into calcite, a well-known phenomenon that is observed if grinding is done with too much force or for too long (Burns and Bredig 1956; Bathurst 1976; Morse and Mackenzie 1990). If contaminating calcite is transformed into aragonite during grinding, it would not then be removed by a CarDS density separation process, thus causing inaccuracies in the ${ }^{14} \mathrm{C}$ date of the sample. We looked for evidence of this transformation and did not see any, by IR or XRD, with the grinding methods we used.

In order to develop a protocol in which the minimum grinding time necessary was used to provide the optimum separation and yield, we also explored correlations of grinding times to particle size, and particle size to separation behavior. Samples of aragonite and calcite were ground and fractionated by size using sieves of mesh sizes ranging from 150 to $38 \mu \mathrm{m}$, and each size fraction then subjected to CarDS. As expected, increased grinding times led to decreased particle size. Each size fraction initially contained a 2:1 mixture of aragonite to calcite. After separation using $4 \mathrm{~mL}$ bromoform with $300 \mu \mathrm{L}$ toluene, the bottom fraction of each sample contained approximately $46 \%$ of the total mass, regardless of particle size. Infrared (IR) spectroscopy also indicated that the bottom fraction contained approximately the same ratio of aragonite to calcite, also regardless of particle size. Therefore, we determined that separation depended only on initial concentrations of the solid and liquid samples and not on small differences in particle size. The only apparent effect that particle size had was in samples that were unsieved, because particles greater than $150 \mu \mathrm{m}$ in size floated or sunk regardless of medium density or solid composition. So, in developing our CarDS protocol we needed simply to eliminate large particles, and we remain confident that the remaining sample fractionates based on density and not on particle size.

In order to maximize sample recovery after grinding while still eliminating error due to inconsistent particle size and minimizing grinding time, it was determined that samples should be sieved once using 150- $\mu \mathrm{m}$ mesh after grinding for $4 \mathrm{~min}$ (two 2-min cycles). Particles above $150 \mu \mathrm{m}$ were considered too large and were discarded, while particles below $150 \mu \mathrm{m}$ continued through the pretreatment process. 


\section{Carbonate Density Separation (CarDS)}

The next step was optimization of the density fractionation method utilized in separating molluscan carbonates. The shells of most species have higher concentrations of aragonite than calcite, and a large number of common species have shells that are exclusively aragonitic (Bøggild 1930). Dates on recrystallized shells can in theory be altered with the incorporation of very small (i.e. 1-5\%) amounts of calcite. However, for ease of IR analysis our initial experiments were performed with a 50:50 mixture of calcite and aragonite. Calcite and aragonite have respective densities of 2.71 and $2.93 \mathrm{~g} / \mathrm{cm}^{3}$, and for the CarDS procedure we used bromoform as a solvent. Bromoform has a density of $2.89 \mathrm{~g} / \mathrm{cm}^{3}$, intermediate between that of calcite and aragonite. It is volatile, so it is easy to remove from samples, and it is relatively inexpensive compared to other heavy liquids. Finally, it is $\mathrm{pH}$-neutral so it will not react with the carbonate in the shells, and it does not dissolve calcium carbonate at all.

Contrary to what may be expected, actual calcite and aragonite samples both float in neat bromoform. All carbonate samples floated in neat bromoform regardless of composition, yet the reason for this anomaly is unknown. Regardless, calcite and aragonite can be separated by CarDS in bromoform if the density of solvent is reduced by the addition of a lower-density miscible liquid until aragonite sinks and calcite floats. Initially, absolute ethanol was used as the secondary liquid because it is miscible with bromoform, has a low density $\left(0.789 \mathrm{~g} / \mathrm{cm}^{3}\right)$, and is relatively cheap and abundant. However, calcium carbonate is sparingly soluble in ethanol, and we found that a fractionation medium containing substantial amounts of ethanol was inefficient at separating carbonates. Therefore, ethanol was replaced by toluene as the secondary fractionation liquid. Toluene is equally as miscible and available as ethanol and has a low density $\left(0.867 \mathrm{~g} / \mathrm{cm}^{3}\right)$, but calcium carbonate is not soluble in toluene, making it a better choice. The density of bromoform can be reduced over a narrow range by careful addition of $\mu \mathrm{L}$ amounts of toluene (Figure 1).

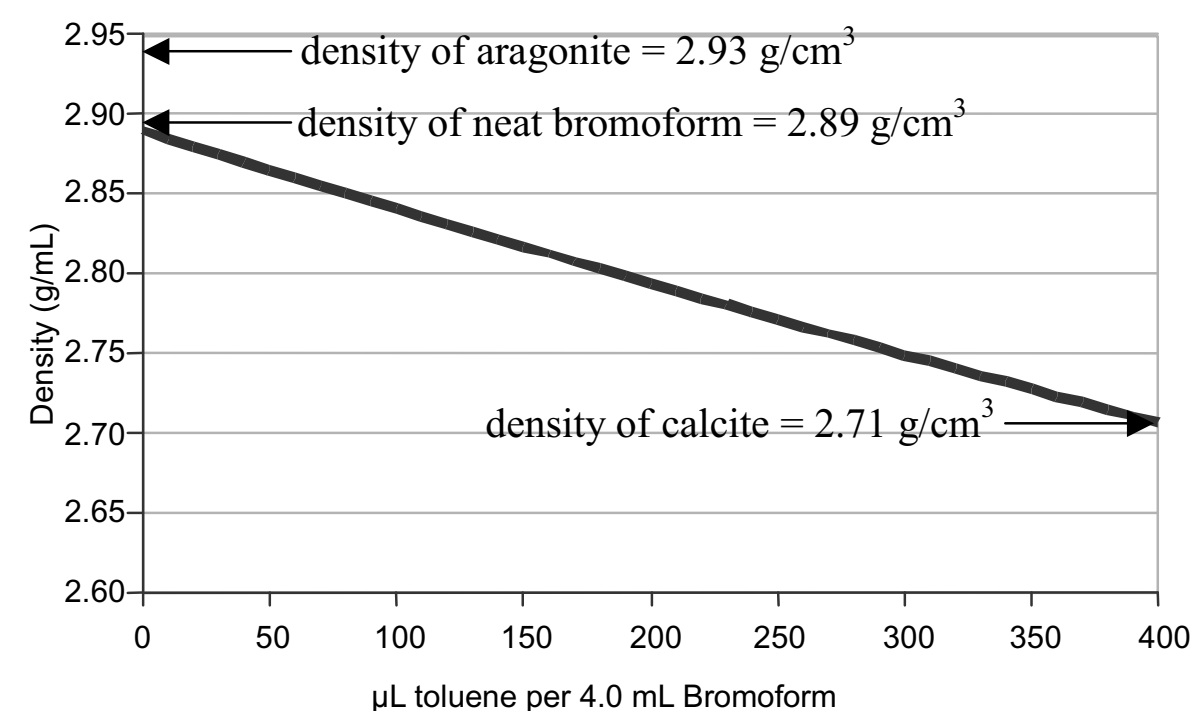

Figure 1 Density of bromoform with toluene addition. The density can be easily altered between $2.89 \mathrm{~g} / \mathrm{cm}^{3}$, the density of neat bromoform, down to $2.71 \mathrm{~g} / \mathrm{cm}^{3}$, the theoretical density of calcite, with addition of $\mu \mathrm{L}$ volumes of toluene. The narrow toluene volume range used in this experiment allows the density of the separation medium to be linearly approximated with the function: $\rho(\mathrm{VT})=-0.000459^{*} \mathrm{VT}+2.89$ where VT $=$ toluene volume in $\mu \mathrm{L}$. Density can be considered linearly proportional to toluene volume over this range. 
The most important variable in CarDS is the density of the separation medium. Since neat bromoform did not separate the carbonates, the best ratio of toluene to bromoform for the separation of calcite and aragonite had to be found. This was done by performing a series of separations that varied only in their toluene content. All separations utilized $4.0 \mathrm{~mL}$ bromoform. Since the density of the separation medium is approximately proportional to the added toluene volume, all samples are enumerated herein according to their toluene content for practicality.

For this technique, the mass of the bottom fraction had to be maximized while simultaneously preventing the introduction of calcite into the bottom layer. If a perfect separation of the 2 carbonates is unachievable, then the next best results would be a separation that introduced only aragonite to the bottom fraction at the expense of reduced yield. We therefore applied the separation method on 50: 50 carbonate samples in media that contained from 100 up to $400 \mu \mathrm{L}$ of toluene. Analysis of the fractions after separation was done using quantitative infrared spectroscopy, and results are shown in Table 1.

Table 1 CarDS of reference samples in bromoform-toluene solutions of different density. ${ }^{\mathrm{a}}$

\begin{tabular}{|c|c|c|c|c|}
\hline $\begin{array}{l}\text { Toluene } \\
\text { added }(\mu \mathrm{L})^{\mathrm{b}}\end{array}$ & $\begin{array}{l}\text { Mass in top } \\
\text { fraction }(\%)^{\mathrm{c}}\end{array}$ & $\begin{array}{l}\text { Mass in bottom } \\
\text { fraction }(\%)^{c}\end{array}$ & $\begin{array}{l}\text { Aragonite in top } \\
\text { fraction }(w t \%)^{d}\end{array}$ & $\begin{array}{l}\text { Aragonite in bottom } \\
\text { fraction }(\mathrm{wt} \%)^{\mathrm{d}}\end{array}$ \\
\hline 100 & 100 & 0 & 56 & - \\
\hline 150 & 98.1 & 1.9 & 55 & 80 \\
\hline 200 & 86.6 & 13.4 & 46 & 75 \\
\hline 250 & 81.2 & 18.8 & 36 & 77 \\
\hline 300 & 69.3 & 30.7 & 31 & 95 \\
\hline 350 & 56.3 & 43.7 & 23 & 77 \\
\hline 400 & 10.5 & 89.5 & 100 & 53 \\
\hline
\end{tabular}

${ }^{a}$ Sample consisted of approximately $440 \mathrm{mg}$ of 1:1 aragonite to calcite.

${ }^{\mathrm{b}}$ Amount of toluene added to $4.0 \mathrm{~mL}$ bromoform.

c Average yield of carbonate from both layers, after filtration, was $94 \%$.

${ }^{\mathrm{d}}$ Determined by quantitative IR spectroscopy as described in the text.

The total mass of the bottom layer clearly increased as toluene volume increased, which lowers the density of the solvent. While the mass of aragonite in the bottom layer increased with the volume of added toluene, so did the amount of calcite, especially when 350 or $400 \mu \mathrm{L}$ of toluene was added. When $300 \mu \mathrm{L}$ of toluene was added, however, the mass of calcite was low while the mass of aragonite remained high, resulting in the best separation (Figure 2A). Figure 2B depicts the percent aragonite in the bottom fraction, and again shows the best separation with the addition of $300 \mu \mathrm{L}$ of toluene (solution density $2.75 \mathrm{~g} / \mathrm{cm}^{3}$ ), as confirmed by its high aragonite concentration of $95 \mathrm{wt} \%$.

\section{AMS Dating of Ancient Shells}

After the method for separating calcite from aragonite was optimized using reference samples, it was applied to ancient shells that have been previously ${ }^{14} \mathrm{C}$ dated or are from archaeological sites whose ages are known (Table 2). Samples analyzed include 3 shells from freshwater bivalves, excavated from the Taperhina site in Brazil (Roosevelt 1991), that have AMS dates that are inconsistent with those previously determined for their site. Two shells from the Viking Bank region off the coast of Norway (Peacock 1995) were also analyzed because their dates are close to the earlier range of dates associated with the inferred migration of anatomically modern humans into Europe (Mellars 2006), one of the wider research themes of dating at the ORAU. One blue mussel shell from Montaña de Oro on the central coast of California (Jones et al. 2008) was analyzed because this species is known to naturally contain calcite and thus can serve as a proxy for a highly recrystallized shell. 

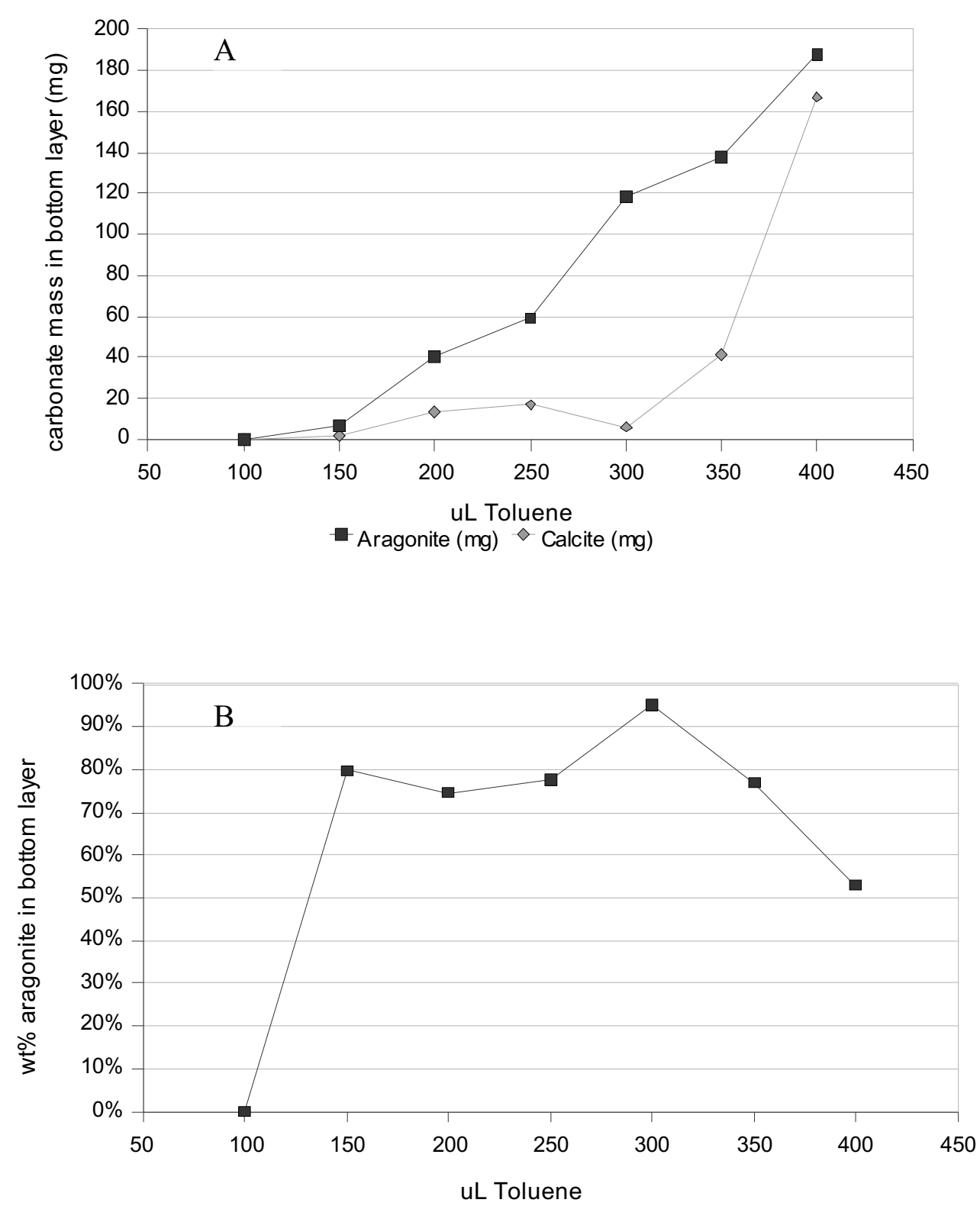

Figure 2 (A) Graphical results of the CarDS optimization showing mass of calcite and aragonite in the bottom layer of each separation, with the volume of toluene added to $4.0 \mathrm{~mL}$ of bromoform. (B) The percentage of aragonite in the bottom fraction with respect to the volume of toluene added. Clearly, the optimum separation is achieved with $300 \mu \mathrm{L}$ of toluene, giving a solvent density of $2.75 \mathrm{~g} / \mathrm{cm}^{3}$. Details of the experiment can be found in the text.

Table 2 Important data on ancient shells used in this project.

\begin{tabular}{llll}
\hline Location & $n$ & Taxonomy & Habitat \\
\hline Taperinha, Brazil & 3 & Hyriidae & Freshwater \\
Viking Bank, Scotland & 2 & Arctica islandica & Marine \\
Montaña de Oro, California & 1 & Mytilus edulis & Marine \\
\hline
\end{tabular}


All samples were ground, sieved, and separated with $300 \mu \mathrm{L}$ of toluene in $4.0 \mathrm{~mL}$ of bromoform. Because infrared spectroscopy cannot directly show calcite concentrations and because of inconsistencies seen in the IR spectra of samples with low concentrations of calcite, the samples were analyzed using XRD at the University of Oxford (Douka et al. 2010). Prior to CarDS, all of the Viking Bank and Taperhina shells appeared by XRD to be mostly aragonitic and the California shell mostly calcitic. After separation, the bottom fraction contained a higher aragonite concentration than the top fraction in all samples. However, in only 3 of the samples (1 from each site) did significant amounts of calcite appear to be removed with CarDS, so these were chosen for AMS analysis. The bottom fractions from the CarDS protocol applied to the Taperinha and Viking Bank samples appeared to be nearly free of calcite (Figure 3), so these were dated directly after a single separation.

(A)

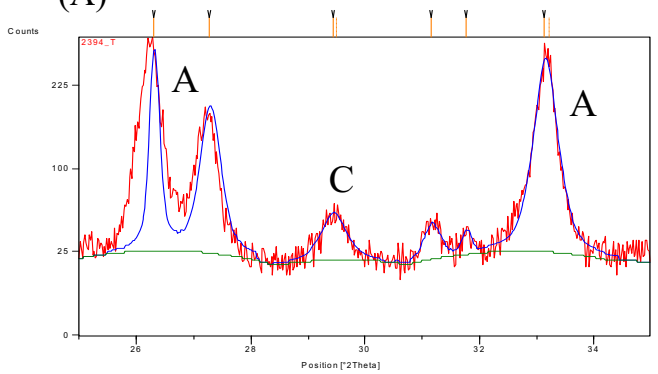

(B)

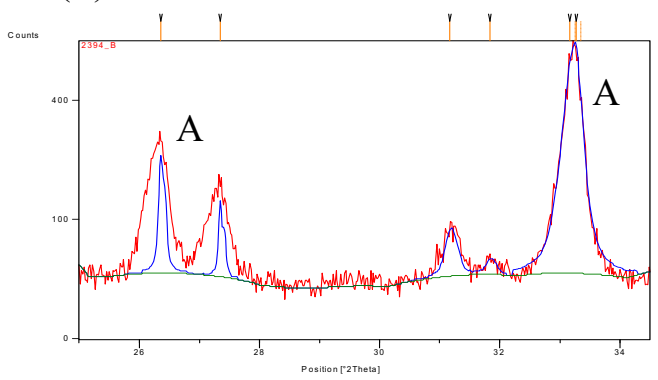

(C)



(D)

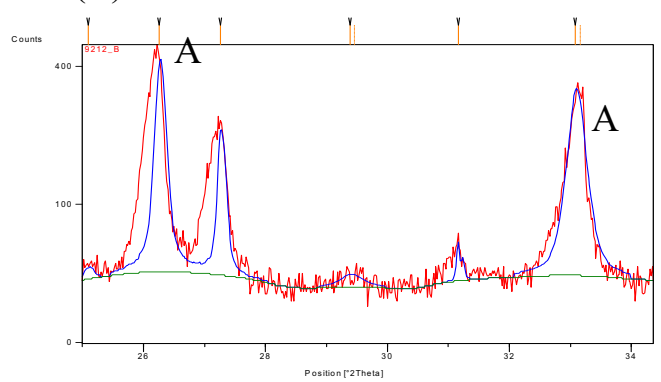

Figure 3 (A) and (B) show the top and bottom layers, respectively, from the CarDS separation of a shell from Taperinha; (C) and (D) the same for a shell from Viking Bank. Characteristic peaks are marked with A for aragonite and C for calcite. Clearly, the bottom layers contain significantly less calcite than the top layers, demonstrating the effectiveness of CarDS.

Because the bottom fraction of the California shell still contained calcite, we chose not to date it directly. We anticipated that a better aragonite purification could be achieved by performing 2 sequential CarDS separations. To determine if this would be beneficial, sequential separations were first attempted on a 1:1 reference sample of aragonite and calcite. The first separation raised the aragonite concentration from $50 \%$ to $95 \%$ in the bottom layer. A second separation performed on the bottom fraction again produced 2 distinct layers. The bottom fraction was shown to be about $99 \%$ aragonite, as determined by XRD analysis. This shows that the second separation does increase aragonite concentrations considerably, though at the expense of reduced yield of carbonate.

The double separation was therefore performed on the California blue mussel shell. The XRD analysis indicated that the upper fraction from the second separation was approximately $50-60 \%$ calcite 
while the bottom fraction contained about $35 \%$ calcite. Even though the bottom fraction still contained significant amounts of calcite, the reduction in yield with each successive separation compelled us to attempt an AMS measurement this fraction, knowing that while not all of the potentially contaminating calcite has been removed, a significant portion had been eliminated and the date ought to be more accurate. The measurement, however, was unable to be completed. The yield of the separations must be significantly improved, or very large samples used, if multiple iterative separations are to be performed to remove large amounts of calcite.

The bottom fractions from the Taperinha and Viking Bank shells were ${ }^{14} \mathrm{C}$ dated (Table 3 ). The aragonite-enriched fractions of both samples returned dates that are younger than the dates obtained for the whole sample. This implies that the isolated aragonite in the shells is younger than the calcite removed from the shells. Furthermore, this may suggest that depleted carbon was incorporated into the shell during the recrystallization or precipitation processes during diagenesis. These conclusions are based on the assumption that all procedures and samples were free of error and contamination. A broader sample set, including AMS dates of calcitic top fractions, may be necessary to determine if these younger dates are more accurate than whole shell dates.

Table 3 AMS ${ }^{14} \mathrm{C}$ dates on molluscan shells pretreated using CarDS in bromoform.

\begin{tabular}{llcc}
\hline Sample & OxA & Original age $^{\mathrm{a}}$ & Age after CarDS \\
\hline Taperinha & OxA-X-2307-27 & $7220 \pm 80$ & $6933 \pm 35$ \\
Viking Bank & OxA-X-2303-34 & $39,650 \pm 750$ & $34,510 \pm 230$ \\
\hline
\end{tabular}

${ }^{a}$ Age originally determined at Oxford for the whole shell Taperinha (OxA-1546), Viking Bank (OxA-8057).

CarDS has the potential to assist in extending the ${ }^{14} \mathrm{C}$ calibration curve beyond that provided by tree rings by assisting in the purification of coral bands that are cross-dated by U/Th dates (Fairbanks et al. 2005). The potential for trace contamination could be avoided using CarDS. In addition, because shell mineral forms from soluble carbonate, measurement of stable carbon and oxygen isotopes can provide an indication of environmental conditions in the region and at the time the shell was formed. The effective use of stable isotopes for obtaining climatic information requires a pretreatment method that eliminates contamination, and CarDS, therefore, has the potential to be widely used by researchers in their investigations of a number of interesting questions.

\section{CONCLUSION}

Molluscan shells are commonly found at coastal archaeological sites around the world. The shells can be ${ }^{14} \mathrm{C}$ dated relatively easily to provide chronometric insight into human activities at the site. However, proper and error-free ${ }^{14} \mathrm{C}$ dating of shells is inhibited by the occurrence of carbonate recrystallization over time. In this paper, we report a carbonate density separation (CarDS) technique that separates calcite from aragonite using a heavy solvent. The technique can be applied to shells that have undergone significant diagenesis to isolate their carbonates and remove any contaminating carbon. Two ${ }^{14} \mathrm{C}$ dates have been obtained for pretreated samples. The dates suggest that both samples might have been contaminated by older calcite that caused the shells to appear older than they actually are in the original dates. Additional dates will be required to determine the robustness of the CarDS method in bromoform, but it shows promise for pretreatment of shells for AMS dating. 


\section{ACKNOWLEDGMENTS}

The authors thank the British Academy Visiting Fellowships award, and the Royal Society Short Visits award, for funding to enable J A T to visit Oxford for this collaborative work. We also thank the University of Scranton for funding, as well as Janice Voltzow, Peter Ditchfield, and David Chivall for helpful discussions and assistance. We acknowledge the shell samples generously provided by Anna Roosevelt and Terry Jones for separation and dating.

\section{REFERENCES}

Bathurst RGC. 1976. Carbonate Sediments and Their Diagenesis. Amsterdam: Elsevier. 658 p.

Bell LS, Cox G, Sealy J. 2001. Determining isotopic life history trajectories using bone density fractionation and stable isotope measurements: a new approach. American Journal of Physical Anthropology 116(1): 66-79.

Berger R, Taylor RE, Libby WF. 1966. Radiocarbon content of marine shells from the California and Mexican west coast. Science 153(3738):864-6.

Bøggild OB. 1930. The shell structure of the mollusks. Det Kongelige Danske videnskabernes selskabs skrifter. Naturvidenskabelig og mathematisk afdeling 9:231-326.

Bronk Ramsey C, Hedges REM. 1997. Hybrid ion sources: radiocarbon measurements from microgram to milligram. Nuclear Instruments and Methods in Physics Research B 123(1-4):539-45.

Burns JH, Bredig MA. 1956. Transformation of calcite to aragonite by grinding. Journal of Chemical Physics 25:1281-3.

Chappell J, Polach HA. 1972. Some effects of partial recrystallisation on ${ }^{14} \mathrm{C}$ dating late pleistocene corals and molluscs. Quaternary Research 2(2):244-52.

dal Negro A, Ungaretti L. 1971. Refinement of the crystal structure of aragonite. The American Mineralogist 56:768-72.

Douka K, Hedges REM, Higham TFG. 2010. Improved AMS ${ }^{14} \mathrm{C}$ dating of shell carbonates using high-precision X-ray diffraction (XRD) and a novel density separation protocol (CarDS). Radiocarbon 52(2-3):73551

Fairbanks RG, Mortlock RA, Chiu T-C, Cao L, Kaplan A, Guilderson TP, Fairbanks TW, Bloom AL, Grootes PM, Nadeau M-J. 2005. Radiocarbon calibration curve spanning 0 to 50,000 years BP based on paired ${ }^{230} \mathrm{Th} /{ }^{234} \mathrm{U} /{ }^{238} \mathrm{U}$ and ${ }^{14} \mathrm{C}$ dates on pristine corals. Quaternary Science Reviews 24(16-17):1781-96.

Falini G, Albeck S, Weiner S, Addadi L. 1996. Control of aragonite or calcite polymorphism by mollusk shell macromolecules. Science 271(5245):67-9.

Goslar T, Pazdur MF. 1985. Contamination studies on mollusk shell samples. Radiocarbon 27(1):33-42.

Henderson GM, Slowey NC, Fleisher MQ. 2001. U-Th dating of carbonate platform and slope sediments. Geochimica et Cosmochimica Acta 65(16):2757-70.

Higham TFG, Hogg AG. 1995. Radiocarbon dating of prehistoric shell from New Zealand and calculation of the $\Delta \mathrm{R}$ value using fish otoliths. Radiocarbon 37(2): 409-16.

Hubbard F, McManus J. 1981. Environmental influences on the shell mineralogy of Mytilus edulis. Geo-Marine Letters 1(3-4):267-9.

Jones TL, Kennett DJ, Kennett JA, Codding BF. 2008. Seasonal stability in Late Holocene shellfish harvesting on the central California coast. Journal of Archaeological Science 35(8):2286-94.

Kato K, Wada H, Fujioka K. 2003. The application of chemical staining to separate calcite and aragonite minerals for micro-scale isotopic analyses. Geochemical Journal 37(2):291-7.

Mangerud J. 1972. Radiocarbon dating of marine shells, including a discussion of apparent age of recent shells from Norway. Boreas 1(2):143-72.

Mellars PA. 2006. A new radiocarbon revolution and the dispersal of modern humans in Eurasia. Nature 439(7079):931-5.

Morse JW, Mackenzie FT. 1990. Geochemistry of Sedimentary Carbonates. Amsterdam: Elsevier. 724 p.

Mutvei H. 1969. On the micro- and ultrastructure of the conchiolin in the nacreous layer of some recent fossil molluscs. Aca Universitatis Stockholmiensis: Stockholm Contributions in Geology 20:1-17.

Peacock JD. 1995. Late Devensian to early Holocene palaeoenvironmental changes in the Viking Bank area, northern North Sea. Quaternary Science Reviews 14(10):1029-42.

Peters W. 1972. Occurrence of chitin in Mollusca. Comparative Biochemistry and Physiology B 41(3):54150.

Pruna M, Faivre R, Chaudron G. 1948. Étude cinétique par dilatométrie isotherme de la transformation de l'aragonite en calcite. Compte rendus de l'Académie des Sciences 227:390-1.

Reimer PJ, McCormac FG. 2002. Marine radiocarbon reservoir corrections for the Mediterranean and Aegean seas. Radiocarbon 44(1):159-66.

Reimer PJ, Reimer RW. 2001. A marine reservoir correction database and on-line interface. Radiocarbon 43(2A): 461-3.

Roosevelt AC, Housely RA, Imazio da Silveira M, Maranca S, Johnson R. 1991. Eighth millennium pottery from a prehistoric shell midden in the Brazilian Amazon. Science 254(5038):1621-4. 
Schmidt M. 2000. Radiocarbon Dating New Zealand Prehistory Using Marine Shell. BAR International Series 842. Oxford: Hadrian Books. $124 \mathrm{p}$.

Shin JY. 2007. Studies in extracting isotopic information from archaeological bone [unpublished D Phil thesis]. University of Oxford.

Stuiver M, Braziunas TF. 1993. Modeling atmospheric ${ }^{14} \mathrm{C}$ influences and ${ }^{14} \mathrm{C}$ ages of marine samples to 10,000 BC. Radiocarbon 35(1):137-89.

Takenaka M, Ikeda M, Terada S. 1999. The use of microwave digestion method for the determination of chemical forms of sodium and chloride ions in seashell structures. Analytical Communications 36:109-11.
Vagenas NV, Gatsouli A, Kontoyannis CG. 2002. Quantitative analysis of synthetic calcium carbonate polymorphs using FT-IR spectroscopy. Talanta 59(4):8316.

Watabe N. 1988. Shell structure. In: Wilbur KN, Trueman ER, Clarke MR, editors. The Mollusca, Volume 11: Form and Function. San Diego: Academic Press. p 69-104.

Wyckoff RWG. 1964. Crystal Structures, Volume 2. New York: John Wiley \& Sons. 362 p.

Yates T. 1986. Studies of non-marine mollusks for the selection of shell samples for radiocarbon dating. Radiocarbon 28(2A):457-63. 